\title{
Effectiveness of a bundled intervention of decolonization and prophylaxis to decrease Gram positive surgical site infections after cardiac or orthopedic surgery: systematic review and meta-analysis
}

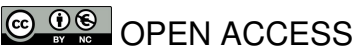

Marin Schweizer assistant professor ${ }^{123}$, Eli Perencevich professor ${ }^{1234}$, Jennifer McDanel student research assistant ${ }^{2}$, Jennifer Carson research assistant ${ }^{1}$, Michelle Formanek student research assistant $^{23}$, Joanne Hafner associate project director ${ }^{5}$, Barbara Braun project director ${ }^{5}$, Loreen Herwaldt professor ${ }^{124}$

${ }^{1}$ University of lowa Carver College of Medicine, lowa City, IA, USA; ${ }^{2}$ University of lowa College of Public Health, lowa City, IA, USA; ${ }^{3}$ Iowa City VA Health Care System, Mailstop 152, 601 Hwy 6 West, lowa City, IA 52246, USA; ${ }^{4}$ Office of Clinical Quality, Safety, and Performance Improvement, and the Department of Medicine, University of lowa Hospitals and Clinics, lowa City, IA, USA; ${ }^{5}$ The Joint Commission, Oakbrook Terrace, IL, USA

\author{
Abstract \\ Objective To evaluate studies assessing the effectiveness of a bundle \\ of nasal decolonization and glycopeptide prophylaxis for preventing \\ surgical site infections caused by Gram positive bacteria among patients \\ undergoing cardiac operations or total joint replacement procedures. \\ Design Systematic review and meta-analysis. \\ Data sources PubMed (1995 to 2011), the Cochrane database of \\ systematic reviews, CINAHL, Embase, and clinicaltrials.gov were
}

searched to identify relevant studies. Pertinent journals and conference abstracts were hand searched. Study authors were contacted if more data were needed.

Eligibility criteria Randomized controlled trials, quasi-experimental studies, and cohort studies that assessed nasal decolonization or glycopeptide prophylaxis, or both, for preventing Gram positive surgical site infections compared with standard care.

Participants Patients undergoing cardiac operations or total joint replacement procedures.

Correspondence to: M Schweizer marin-schweizer@uiowa.edu

Extra material supplied by the author (see http://www.bmj.com/content/346/bmj.f2743?tab=related\#webextra)

Supplementary table

Supplementary figures

Video on bmj.com (see also http://bmj.com/video)

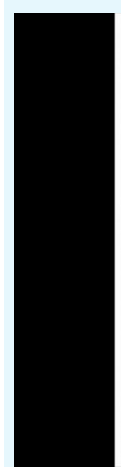

- $85 \%$ of surgical site infections involving S. aureus come from the patient's own bacteria 
Data extraction and study appraisal Two authors independently extracted data from each paper and a random effects model was used to obtain summary estimates. Risk of bias was assessed using the Downs and Black or the Cochrane scales. Heterogeneity was assessed using the Cochran $Q$ and $I^{2}$ statistics.

Results 39 studies were included. Pooled effects of 17 studies showed that nasal decolonization had a significantly protective effect against surgical site infections associated with Staphylococcus aureus (pooled relative risk $0.39,95 \%$ confidence interval 0.31 to 0.50 ) when all patients underwent decolonization $(0.40,0.29$ to 0.55$)$ and when only $S$ aureus carriers underwent decolonization $(0.36,0.22$ to 0.57$)$. Pooled effects of 15 prophylaxis studies showed that glycopeptide prophylaxis was significantly protective against surgical site infections related to methicillin (meticillin) resistant $S$ aureus (MRSA) compared with prophylaxis using $\beta$ lactam antibiotics $(0.40,0.20$ to 0.80$)$, and a non-significant risk factor for methicillin susceptible $S$ aureus infections $(1.47,0.91$ to 2.38). Seven studies assessed a bundle including decolonization and glycopeptide prophylaxis for only patients colonized with MRSA and found a significantly protective effect against surgical site infections with Gram positive bacteria $(0.41,0.30$ to 0.56$)$.

Conclusions Surgical programs that implement a bundled intervention including both nasal decolonization and glycopeptide prophylaxis for MRSA carriers may decrease rates of surgical site infections caused by $S$ aureus or other Gram positive bacteria.

\section{Introduction}

Surgical site infections after cardiac operations or total joint arthroplasties are associated with severe outcomes, including important increases in hospital length of stay, readmission rates, healthcare costs, and mortality rates..$^{1-3}$ Many such infections are thought to be preventable. Consequently, the US Centers for Medicare and Medicaid Services no longer reimburse hospitals for some surgical site infections, including mediastinitis, which per patient can cost over $\$ 40000$ ( $£ 25800$; $€ 30700) .{ }^{4}$ The high costs of these infections are also detrimental to publicly funded healthcare systems, such as the UK's National Health Service. Additionally, in this era of mandatory reporting, hospitals may soon be required to report rates of surgical site infections publicly, which could lead to more financial repercussions if patients or insurers choose institutions with lower infection rates. Therefore, implementation of an evidence based bundle of interventions to decrease surgical site infections could benefit both patients and hospitals.

The Surgical Care Improvement Project measures recommend preoperative prophylaxis with a $\beta$ lactam antibiotic for cardiac and orthopedic procedures, unless the patient is known to be at high risk for methicillin (meticillin) resistant Staphylococcus aureus (MRSA) infection or the hospital has a high rate of MRSA related surgical site infections. In those cases, glycopeptide antibiotics such as vancomycin are recommended. ${ }^{67}$ Yet, in the wake of extensive publicity about MRSA, many hospitals have implemented additional interventions to prevent surgical site infections with Gram positive bacteria-particularly MRSA — such as providing vancomycin prophylaxis for all surgical patients or decolonizing patients using nasal mupirocin to prevent transmission of $S$ aureus from the nose to the surgical site. ${ }^{8}{ }^{9}$ However, despite guidelines and numerous studies dealing with the effectiveness of these interventions, researchers and clinicians have not reached consensus on how to optimally prevent Gram positive surgical site infections, and practices are often inconsistent both within and across hospitals. ${ }^{6-12}$

Recently, bundled interventions have greatly decreased the rates of specific healthcare associated infections such as central line related bloodstream infections and MRSA infections. ${ }^{13}{ }^{14} \mathrm{~A}$ bundled intervention that goes beyond measures advocated by the Surgical Care Improvement Project and includes nasal decolonization and glycopeptide prophylaxis could potentially reduce rates of Gram positive surgical site infections, specifically those associated with $S$ aureus. An assessment of the effectiveness of this bundled intervention and the individual components of the bundle could greatly inform clinical practice. We systematically reviewed and evaluated all studies that assessed the effectiveness of a bundle that included both nasal decolonization and glycopeptide prophylaxis and studies that assessed individual components of the bundle, for preventing Gram positive surgical site infections among patients who underwent cardiac operations or total joint arthroplasties. We also evaluated the effectiveness of these interventions for preventing Gram positive surgical site infections caused by either MRSA or methicillin susceptible $S$ aureus (MSSA) surgical site infections. We hypothesized that a bundle that included nasal decolonization and glycopeptide prophylaxis would result in a lower incidence of Gram positive surgical site infections compared with standard care.

\section{Methods}

\section{Search strategy}

These meta-analyses were conducted according to the MOOSE and PRISMA checklists. ${ }^{15}{ }^{16} \mathrm{We}$ included all research studies that assessed nasal decolonization or glycopeptide prophylaxis, or both for the prevention of surgical site infections with Gram positive bacteria. We decided a priori to include both randomized controlled trials and observational studies (for example, quasi-experimental studies) because randomized controlled trials of bundles to prevent infections often are thought not to be logical because numerous sites are necessary for a cluster randomized trial and the trial would be prohibitively expensive. ${ }^{17}$

Guided by a librarian we identified potentially relevant studies through a structured literature review. Three authors (JK, JC, MS) searched the PubMed databases, the Cochrane database of systematic reviews, the Cumulative Index to Nursing and Allied Health Literature (CINAHL), Embase, and clinicaltrials.gov for articles published from 1 January 1995 through 31 January 2012, with keywords and medical subject heading $(\mathrm{MeSH})$ terms "surgical wound infection" AND "screening" or "surveillance" or "prophylactic" or "prophylaxis" or "antimicrobial" or "antibiotic" AND "cardiac" or "orthopedic". We also hand searched journals recommended by a technical expert panel of surgeons and infectious disease physicians: Infection Control and Hospital Epidemiology, Clinical Infectious Diseases, Journal of Hospital Infection, American Journal of Infection Control, Annals of Thoracic Surgery, Journal of Thoracic and Cardiovascular Surgery, American Journal of Respiratory and Critical Care Medicine, Proceedings of the American Thoracic Society, Journal of Arthroplasty, and Journal of Bone \& Joint Surgery.

We reviewed the reference lists of retrieved articles to identify studies that were not obtained from the preliminary literature searches. To find abstracts of unpublished studies we then reviewed proceedings from conferences that were recommended by the technical expert panel: the Interscience Conference on Antimicrobial Agents and Chemotherapy, the Society for Healthcare Epidemiology of America annual meeting, the American Academy of Orthopaedic Surgeons annual meeting, and the American Thoracic Society annual meeting. If an abstract or article did not provide sufficient information to be 
included in the meta-analyses (for example, the number of Gram positive surgical site infections), the current investigators contacted the study's authors for the necessary information.

\section{Inclusion and exclusion criteria}

Studies were included if they met the following criteria: published in English, assessed Gram positive surgical site infections as an outcome, included a comparison group, and patient populations concerned adults who underwent cardiac procedures, total joint arthroplasty, or general orthopedic procedures.

We excluded studies if they were case reports, commentaries, guidelines, editorials, animal studies, risk factor studies, studies that did not include an intervention, or pediatric studies. Additionally we excluded studies if they assessed antimicrobial agents for the treatment of surgical site infections, had insufficient data, or were mathematical modeling studies.

\section{Outcomes of interest}

The primary outcome of interest was surgical site infections caused by Gram positive bacteria. Secondary outcomes of interest included surgical site infections caused by a specific Gram positive organism-S aureus, including methicillin (meticillin) resistant $S$ aureus (MRSA) and methicillin susceptible $S$ aureus (MSSA). We chose surgical site infections caused by $S$ aureus as secondary outcomes for two reasons. Firstly, many studies utilize the interventions of interest-decolonization and glycopeptide prophylaxis-to prevent $S$ aureus surgical site infections specifically. Secondly, $S$ aureus is the most common cause of surgical site infections, thus it is important to evaluate such infections alone. ${ }^{18}$ Additionally, to perform a preliminary evaluation of whether interventions focused on reducing the risk of $S$ aureus surgical site infections might increase the risk of surgical site infections caused by other pathogens, we also assessed the association between the interventions of interest and all surgical site infections and those caused by Gram negative bacteria. However, we did not include the latter outcomes in our systematic literature review or inclusion and exclusion criteria.

\section{Data extraction and risk of bias assessment}

We screened the titles and abstracts from 1423 articles to assess whether they met the inclusion or exclusion criteria. If the screeners could not determine whether the study was relevant, two investigators reviewed the article in detail. Two of the three independent reviewers (LH, MS, EP) abstracted data for each article and a third party (MF) compared the two sets of data for agreement. The first author reviewed all inconsistent assessments and the three independent reviewers resolved their disagreements by consensus.

The three independent reviewers abstracted data from the study papers on year of publication, study design, type of surgical procedure assessed, intervention assessed, outcomes assessed, method of measuring the outcome (for example, by whom, definition of surgical site infections), inclusion and exclusion criteria for each study, and the associations between interventions and surgical site infection rates. The reviewers also determined whether a bundled approach was used. They reviewed articles that assessed nasal decolonization as an intervention to determine the patient population decolonized (for example, all patients, only $S$ aureus carriers, only MRSA carriers), antimicrobial used (for example, mupirocin, chlorhexidine gluconate), and the dosing regimen. The reviewers also read articles that assessed preoperative prophylaxis using glycopeptides to identify which glycopeptide was used (for example, vancomycin, teicoplanin), and which antimicrobial agent (for example, cefazolin) served as the comparator.

The investigators used the Cochrane risk of bias tool to assess randomized controlled trials, ${ }^{19}$ and the Downs and Black scoring system to assess the risk of bias in the observational studies..$^{20}$ The Downs and Black scoring system is applicable for both cohort studies and before and after quasi-experimental studies. We evaluated each study using the subscales in the Downs and Black tool that assessed reporting, external validity, internal validity-bias, internal validity-confounding, and power. Both scoring systems are valid and reliable and have been widely used by other investigators.

\section{Statistical analysis}

Using the extracted raw data, we calculated the natural log of the relative risk and variance..$^{21}$ None of the studies included in our review adjusted statistically for potential confounders. Thus we only included raw data in the analyses. Pooled relative risk estimates from random effect models are presented..$^{21}{ }^{22}$ In addition, we performed sensitivity analyses in which we used fixed effect models to determine both pooled relative risk estimates and pooled risk difference estimates.

We used Microsoft Excel 2007 and the Cochrane Review Manager (RevMan) version 5.1. ${ }^{23}$ To assess heterogeneity, we used the Cochran Q statistic, the $\mathrm{I}^{2}$ statistic, and the results of stratified analyses based on the following a priori categories: organism causing the surgical site infections (all $S$ aureus, MRSA only, MSSA only), patient population decolonized (all patients, $S$ aureus carriers, MRSA carriers), and study design (randomised controlled trial versus quasi-experimental study). We visually inspected funnel plots for symmetry to evaluate possible publication bias.

\section{Results}

Figure $1 \Downarrow$ summarises the search and review process. Among the 74 articles reviewed in detail, 39 studies on independent populations reported data that contributed to the meta-analyses. Among the 39 studies that met the inclusion criteria, 17 assessed the effectiveness of nasal decolonization compared with standard of care, ${ }^{24-40} 15$ compared glycopeptide prophylaxis with $\beta$ lactam prophylaxis, ${ }^{41-55}$ and seven assessed a bundle in which patients were screened for nasal colonization with S aureus, decolonized, and MRSA carriers given glycopeptide prophylaxis and all other surgical patients given $\beta$ lactam prophylaxis. ${ }^{56-62}$ Of the 15 study authors who we attempted to contact, 12 responded. Three authors did not have the necessary data, but nine shared their data.

Of the 39 studies included in the meta-analysis, 13 were randomized controlled trials and 26 were observational studies. Thirty six of these studies were published in peer reviewed journals, whereas three were presented in abstract form only (see supplementary table 1). Overall, the randomized controlled trials included in this meta-analysis had a fairly low risk of bias (fig $2 \Downarrow$ ). Table $1 \Downarrow$ presents the Downs and Black subscale scores for each observational study. In general, the observational studies had good external validity but poor internal validity.

\section{Bundle including decolonization and glycopeptide prophylaxis meta-analysis}

Seven quasi-experimental studies assessed infection prevention bundles that utilized both nasal decolonization and glycopeptide prophylaxis. Two studies decolonized MRSA carriers only, two 
decolonized MRSA carriers and MSSA carriers, and three decolonized all patients in the intervention group; in one of the latter studies, mupirocin treatment was stopped if the results of nares cultures were negative. MRSA carriers received vancomycin for prophylaxis in four studies, vancomycin and cefazolin in two studies, and teicoplanin in one study (see supplementary table 1a). Two of these studies included cardiac operations, three included total joint arthroplasties, and two included general orthopedic surgical procedures (see supplementary table 1a). All of these studies were sufficiently homogeneous and thus could be included in the meta-analyses to assess all outcomes $\left(\mathrm{I}^{2}=0 \%, \mathrm{P}>0.30\right)$.

In this meta-analysis, the decolonization and prophylaxis bundle was significantly protective against surgical site infections caused by both Gram positive bacteria (fig $3 \Downarrow$ ) and $S$ aureus (table $2 \Downarrow$ ). Although this bundle was shown to be significantly protective against MRSA and MSSA surgical site infections, the effect estimate for MRSA surgical site infections was stronger than for MSSA surgical site infections, possibly because glycopeptide prophylaxis was used to prevent the MRSA surgical site infections (table 2).

\section{Nasal decolonization meta-analysis}

Of the 17 studies that assessed nasal decolonization, five were randomised controlled trials and 12 were quasi-experimental studies. Ten studies included cardiac operations and three assessed total joint arthroplasties. Since the number of studies that assessed total joint arthroplasty was small, we also included the seven studies that assessed nasal decolonization for general orthopedic operations. The decolonization regimen varied across studies. However, 16 of 17 studies used mupirocin ointment to decolonize the nares and one study used nasal chlorhexidine gluconate. (See supplementary table $1 \mathrm{~b}$ for details of these studies.)

The meta-analysis of these 17 studies found that nasal decolonization was associated with a decreased rate of Gram positive surgical site infections and that these studies were significantly heterogeneous (fig $4 \Downarrow$ ). When surgical site infections caused by $S$ aureus were assessed as the outcome among the 17 studies, the results were homogenous $\left(\mathrm{I}^{2}=12 \%\right.$; $\mathrm{P}=0.32$ ) and nasal decolonization was associated with a significantly lower risk of $S$ aureus surgical site infections (table 2 ). The pooled relative risks were similar when study results were stratified by surgical site infections caused by MRSA or MSSA, suggesting decolonization was protective against either. Additionally, nasal decolonization was significantly protective against $S$ aureus surgical site infections among patients who underwent orthopedic or cardiac surgical procedures (table 2). When only randomized controlled trials were assessed, nasal decolonization was associated with a statistically significant decline in $S$ aureus surgical site infections, but this protective association was not statistically significant for all Gram positive surgical site infections (table 2).

In 11 studies, all patients in the intervention group were decolonized with an intranasal antimicrobial agent regardless of whether they carried S aureus in their nares. When the effects of these studies were pooled, nasal decolonization was associated with a significant decrease in $S$ aureus surgical site infections (pooled relative risk $0.40,95 \%$ confidence interval 0.29 to 0.55 ). In contrast, six other studies decolonized only patients who carried $S$ aureus in their nares. The pooled effect estimate of these six studies indicated that this approach was also associated with a significant decrease in $S$ aureus surgical site infections $(0.36,0.22$ to 0.57$)$.
Six studies assessed nasal decolonization plus skin decontamination with either chlorhexidine gluconate or triclosan. The pooled effect estimate for this intervention was consistent with a protective effect against $S$ aureus surgical site infections $(0.29,0.19$ to 0.44$)$. The meta-analysis of the 11 other studies, which assessed decolonization alone without skin decontamination, also found a statistically significant protective effect against $S$ aureus surgical site infections $(0.70,0.50$ to 0.97). However, none of the studies compared nasal decolonization alone with nasal decolonization plus skin decontamination.

\section{Glycopeptide prophylaxis meta-analysis}

Of the 15 studies assessing the effectiveness of preoperative glycopeptide prophylaxis, 12 assessed vancomycin and three assessed teicoplanin. Of the 15 studies, eight were randomised controlled trials, four were quasi-experimental studies, and three were retrospective cohort studies; eight studies included cardiac operations, five included total joint arthroplasties, and two assessed both. (See supplementary file table 1c for details of these studies.)

The meta-analysis of the association between glycopeptide prophylaxis and surgical site infections found that this intervention was significantly protective against MRSA surgical site infections compared with $\beta$ lactam prophylaxis (table 2 ). Conversely, glycopeptide prophylaxis was a risk factor for MSSA surgical site infections, although this finding was not statistically significant (table 2). However, among all studies and among only randomized controlled trials, glycopeptide prophylaxis was not associated with significantly decreased surgical site infection rates caused by Gram positive bacteria or by $S$ aureus (fig $5 \Downarrow$ ).

Six studies compared the efficacy of prophylaxis with a combination of a glycopeptide plus another antimicrobial agent (for example, rifampin, clindamycin, cefuroxime, cefazolin, ticarcillin/clavulante) and prophylaxis with a $\beta$ lactam antibiotic only. When those six studies were pooled, the combination prophylaxis was significantly protective against Gram positive surgical site infections (pooled relative risk $0.22,0.09$ to 0.55 ). Conversely, when the nine studies that compared glycopeptide prophylaxis alone with $\beta$ lactam prophylaxis were combined, glycopeptide prophylaxis was a risk factor for Gram positive surgical site infections, though this result did not reach statistical significance $(1.19,0.99$ to 1.45$)$.

\section{Sensitivity analyses}

For each meta-analysis we calculated fixed effects relative risks and fixed effects risk differences. The fixed effects relative risks were nearly identical to the random effects relative risks for the associations between nasal decolonization and Gram positive surgical site infections (fixed effects $0.44,0.36$ to 0.54 ), between glycopeptide prophylaxis and Gram positive surgical site infections (fixed effects $0.89,0.75$ to 1.06 ), and between the bundle and Gram positive surgical site infections (fixed effects $0.40,0.30$ to 0.54 ). Nasal decolonization alone and the bundle were both associated with a significantly decreased risk of Gram positive surgical site infections (risk difference $-0.0107,95 \%$ confidence interval -0.0134 to -0.0080 , and $-0.0057,-0.0077$ to -0.0038 , respectively). Glycopeptide prophylaxis was not associated with a statistically significant decrease in the risk of Gram positive surgical site infections $(-0.0036,-0.0088$ to 0.0016).

Additionally, to evaluate whether interventions that focused on decreasing $S$ aureus surgical site infections might increase the 
rate of surgical site infections caused by other organisms, we evaluated the studies to assess the association between the interventions of interest and all surgical site infections and surgical site infections specifically caused by Gram negative bacteria. Nasal decolonization was associated with a significantly protective effect of reducing all surgical site infections (pooled relative risk $0.60,95 \%$ confidence interval 0.49 to 0.73 ) and Gram negative surgical site infections $(0.15$, 0.03 to 0.74 ). Compared with $\beta$ lactam prophylaxis, glycopeptide prophylaxis was not statistically significantly associated with changes in all surgical site infections $(1.00,0.70$ to 1.42$)$ or Gram negative surgical site infections $(0.90,0.50$ to 1.61$)$.The bundle was significantly protective against all surgical site infections $(0.47,0.37$ to 0.60$)$ but was not significantly associated with changes in Gram negative surgical site infections $(0.73,0.39$ to 1.36$)$ nor Gram positive surgical site infections caused by pathogens other than $S$ aureus (1.02, 0.50 to 2.05).

\section{Publication bias assessment}

Funnel plots assessing publication bias were visibly symmetrical for studies of nasal decolonization and studies of the decolonization and glycopeptide prophylaxis bundle (see supplementary figure 1). The funnel plot was visibly asymmetrical for studies of glycopeptide prophylaxis, suggesting that small studies that demonstrated the superiority of $\beta$ lactam prophylaxis over glycopeptide prophylaxis may not have been published. However, if studies showing the superiority of $\beta$ lactam prophylaxis were published, these studies would add further evidence that glycopeptide prophylaxis is not superior to $\beta$ lactam prophylaxis for the prevention of surgical site infections.

\section{Discussion}

Although multiple studies have assessed the efficacy of interventions to prevent surgical site infections caused by Gram positive bacteria, these interventions are not uniformly applied to surgical patients. Our results showed that nasal decolonization was associated with decreased rates of Gram positive surgical site infections and Staphylococcus aureus surgical site infections among patients undergoing cardiac or orthopedic surgical procedures. However, these results remained statistically significant for $S$ aureus surgical site infections, though not all Gram positive surgical site infections, when the meta-analysis was limited to randomized controlled trials. Additionally, a bundle that included nasal decolonization and glycopeptide prophylaxis for patients who carried methicillin (meticillin) resistant $S$ aureus (MRSA) was associated with significantly decreased rates of surgical site infections caused by Gram positive bacteria and by $S$ aureus.

We also found that routine use of prophylactic glycopeptides protected against MRSA infections but not against all Gram positive surgical site infections. Additionally, dual prophylaxis with a glycopeptide and another antimicrobial agent seemed to be more protective against Gram positive surgical site infections than prophylaxis with glycopeptides alone. This finding is consistent with studies of methicillin susceptible $S$ aureus (MSSA) bacteremia, which found that vancomycin is less effective than a $\beta$ lactam antibiotic for treating MSSA infections. ${ }^{63}{ }^{64}$ These results are similar to the conclusions of a recent review article, which stated that vancomycin is not recommended for preoperative prophylaxis but may be considered as a component of an MRSA bundle to prevent surgical site infections. ${ }^{65}$
Our meta-analyses were the first to assess a bundle that included nasal decolonization and targeted glycopeptide prophylaxis for MRSA carriers. Other meta-analyses have assessed nasal decolonization or glycopeptide prophylaxis alone, ${ }^{66-68}$ and our results confirm the findings of the previous studies and extend these by including the results of recent studies. Future meta-analyses should assess other outcomes associated with these interventions. These outcomes could include duration of hospital stay since one group of researchers found that the mean duration of hospital stay was significantly shorter in those randomized to mupirocin and chorhexidine gluconate rather than to placebo. ${ }^{27}$ Future meta-analyses should also confirm our preliminary findings that these interventions do not open a niche for pathogens other than $S$ aureus to fill, and should also analyze other patient populations such as those requiring trauma surgery to determine if these findings are generalizable to other surgical specialties.

Nasal decolonization protected against $S$ aureus surgical site infections when all patients were decolonized and when only $S$ aureus carriers were decolonized. Routine nasal decolonization of all surgical patients may be easier to implement and more cost effective than using cultures or polymerase chain reaction testing to screen patients preoperatively.$^{69}$ None the less, it may be prudent to reserve mupirocin decolonization for patients who carry $S$ aureus to prevent widespread mupirocin resistance. ${ }^{70}$ Similarly, it may be prudent to do further research on targeted prophylaxis with vancomycin before including this bundle in clinical practice. Of note, the pooled relative risks assessing Gram positive surgical site infections were identical for both the decolonization studies and the bundle studies. Thus high quality studies such as cluster randomized trials are still needed to determine whether adding glycopeptide prophylaxis to nasal decolonization will further decrease the incidence of Gram positive surgical site infections.

In our sensitivity analyses we found that nasal decolonization was associated with a $1 \%$ risk difference and the bundle was associated with a $0.5 \%$ risk difference in Gram positive surgical site infections. Although these differences seem small, they are clinically significant considering that cardiac and orthopedic operations are common and surgical site infections are associated with considerable morbidity. Each year, approximately 300000 cardiac operations and approximately 900000 total joint arthroplasties are done in the United States alone. ${ }^{71}$ Thus these interventions could prevent 6000 to 12000 surgical site infections per year in the United States and even more worldwide.

\section{Limitations of this study}

Our study has some limitations. Firstly, meta-analyses are only as valid as the studies that contribute to the pooled risk ratio. We included many studies that were simple before and after quasi-experimental studies. Additionally, none of the included studies adjusted statistically for potential confounders, thus confounding may be problem, especially among the observational studies. To mitigate this limitation, we performed subset analyses on the results of only randomized controlled trials. Secondly, we did not include studies that did not report or could not provide specific data on Gram positive infections, thus we may have excluded important decolonization and prophylaxis studies. However, nine of 15 contacted investigators submitted additional data for inclusion in the analyses. Thirdly, studies of the association between interventions and Gram positive surgical site infections were heterogeneous, and thus some of the meta-analysis results should be interpreted with caution. Once these studies were stratified by potential sources 
of heterogeneity, the stratified subsets were homogeneous. For example, nasal decolonization aims to decrease the incidence of endogenous $S$ aureus surgical site infections. The association between nasal decolonization and Gram positive surgical site infections may have been different for studies in which $S$ aureus caused most Gram positive surgical site infections compared with studies in which surgical site infections due to other Gram positive pathogens were common. Thus we limited heterogeneity by doing subset analyses that separated studies focusing on $S$ aureus surgical site infections from those focusing on all Gram positive surgical site infections.

\section{Conclusion}

Surgical site infections caused by Gram positive bacteria may be prevented by decolonizing patients who carry $S$ aureus in their nares and potentially by adding a glycopeptide to the usual prophylaxis using $\beta$ lactam antibiotics for MRSA carriers. High quality randomized controlled trials or cluster randomized trials should be performed to further assess this bundle.

We thank the following for contributing additional data from their research, which allowed us to improve the quality of the study: Trish M Perl, M Bridget Zimmerman, Karolin Graf, Kalpana Gupta, Lorraine Hutzler, Urs Niederhauser, Ann Bull, Scott Sporer, Lonneke Bode, and Jenni Steinbrunner; and Michele Bozikis, Edward Septimus, and the Technical Expert Panel, including Michael Banbury, Dale Bratzler, Joseph Buckwalter, E Patchen Dellinger, Richard Embrey, Stephan Harbarth, Keith Kaye, Matthew Koff, Randy Loftus, Vincent Pellegrini, James Steinberg, and Edward Wong who contributed to this work; and the lowa City VA Health Care System for its support. This study was presented in part at the 49th annual Infectious Diseases Society of America meeting. Boston, MA, October, 2011. This research was conducted by investigators at the University of lowa and The Joint Commission under contract to the Agency for Healthcare Research and Quality. The authors of this article are responsible for the content. No statement may be construed as the official position of the Agency for Healthcare Research and Quality of the US Department of Health and Human Services.

Contributors: MLS, ENP, JH, BB, and LAH designed the study. MLS, $\mathrm{JM}$, and JC performed the literature search. MLS, ENP, and LAH abstracted data. MF compared reviewer forms and assisted in the meta-analyses. MLS performed the meta-analyses. MLS, ENP, JH, BB, and $\mathrm{LAH}$ wrote the report. All authors read and approved the final version before submission. MLS is the guarantor.

Funding: This project was funded by the Agency for Healthcare Research and Quality (contract No HHSA290200600021I) of the US Department of Health and Human Services. The sponsors played no role in the study design, data collection and analysis, or decision to submit the article for publication. MLS was supported by the University of lowa clinical and translational science award (NIH/NCRR-3KL2

RR024980-04S1). ENP was funded through a VA Health Services and Research and Development Service grant (No 09-099).

Competing interests: All authors have completed the ICMJE uniform disclosure form at www.icmje.org/coi_disclosure.pdf (available on request from the corresponding author) and declare: no support from any company for their submitted work; no financial relationships with any companies that might have an interest in the submitted work in the previous three years; and no other relationships or activities that could appear to have influenced the submitted work.

Ethical approval: Not required.

Data sharing: No additional data available.

1 Whitehouse JD, Friedman ND, Kirkland KB, Richardson WJ, Sexton DJ. The impact of surgical-site infections following orthopedic surgery at a community hospital and a university hospital: adverse quality of life, excess length of stay, and extra cost. Infect Control Hosp Epidemiol 2002;23:183-9.

2 Bellchambers J, Harris JM, Cullinan P, Gaya H, Pepper JR. A prospective study of wound infection in coronary artery surgery. Eur J Cardiothorac Surg 1999;15:45-50.

3 Ridderstolpe L, Gill H, Granfeldt H, Ahlfeldt H, Rutberg H. Superficial and deep sternal wound complications: incidence, risk factors and mortality. Eur J Cardiothorac Surg 2001;20:1168-75.

4 Centers for Medicare and Medicaid Services. CMS improves patient safely for Medicare and Medicaid by addressing never events. 2012. www.cms.hhs.gov/apps/media/press/ factsheet.asp? Counter $=3224 \&$ intNumPerPage $=10 \&$ checkDate $=\&$ checkKey $=\&$ srchType $=1 \&$ numDays $=3500 \&$ srchOpt $=0 \&$ srchData $=\&$ keywordType $=A l l \&$ chkNews Type $=6 \&$ intPage $=\&$ showAll=\&pYear $=\& y e a r=\& d e s c=$ false $\&$ cboOrder $=$ date

5 Taylor GJ, Mikell FL, Moses HW, Dove JT, Katholi RE, Malik SA, et al. Determinants of hospital charges for coronary artery bypass surgery: the economic consequences of postoperative complications. Am J Cardiol 1990;65:309-13.

6 Bratzler DW, Houck PM, Surgical Infection Prevention Guideline Writers Workgroup. Antimicrobial prophylaxis for surgery: an advisory statement from the National Surgical Infection Prevention Project. Am J Surg 2005;189:395-404.

7 Bratzler DW, Houck PM, Surgical Infection Prevention Guidelines Writers Workgroup, American Academy of Orthopaedic Surgeons, American Association of Critical Care Nurses, American Association of Nurse Anesthetists. Antimicrobial prophylaxis for surgery: an advisory statement from the National Surgical Infection Prevention Project. Clin Infect Dis 2004;38:1706-15

8 Garey KW, Lai D, Dao-Tran TK, Gentry LO, Hwang LY, Davis BR. Interrupted time series analysis of vancomycin compared to cefuroxime for surgical prophylaxis in patients undergoing cardiac surgery. Antimicrob Agents Chemother 2008;52:446-51.

9 Diekema D, Johannsson B, Herwaldt L, Beekmann S, Jernigan J, Kallen A, et al. Current practice in Staphylococcus aureus screening and decolonization. Infect Control Hosp Epidemiol 2011;32:1042-4.

10 Mangram AJ, Horan TC, Pearson ML, Silver LC, Jarvis WR. Guideline for prevention of surgical site infection, 1999. Hospital Infection Control Practices Advisory Committee. Infect Control Hosp Epidemiol 1999;20:250-78.

11 Engelman R, Shahian D, Shemin R, Guy TS, Bratzler D, Edwards F, et al. The Society of Thoracic Surgeons practice guideline series: antibiotic prophylaxis in cardiac surgery, part II: antibiotic choice. Ann Thorac Surg 2007;83:1569-76.

12 American Academy of Orthopaedic Surgeons. Recommendations for the use of intravenous antibiotic prophylaxis in primary total joint arthroplasty. Information statement 1027. 2012. www.aaos.org/about/papers/advistmt/1027.asp.

13 Pronovost P, Needham D, Berenholtz S, Sinopoli D, Chu H, Cosgrove S, et al. An intervention to decrease catheter-related bloodstream infections in the ICU. N Engl J Med 2006;355:2725-32.

14 Jain R, Kralovic SM, Evans ME, Ambrose M, Simbartl LA, Obrosky DS, et al. Veterans Affairs initiative to prevent methicillin-resistant Staphylococcus aureus infections. N Engl J Med 2011;364:1419-30.

15 Stroup DF, Berlin JA, Morton SC, Olkin I, Williamson GD, Rennie D, et al. Meta-analysis of observational studies in epidemiology: a proposal for reporting. Meta-analysis Of Observational Studies in Epidemiology (MOOSE) group. JAMA 2000;283:2008-12.

16 Moher D, Liberati A, Tetzlaff J, Altman DG, the PRISMA Group. Preferred Reporting Items for Systematic Reviews and Meta-Analyses: the PRISMA statement. PLoS Med 2009;6:e1000097.

17 Harris AD, Bradham DD, Baumgarten M, Zuckerman IH, Fink JC, Perencevich EN. The use and interpretation of quasi-experimental studies in infectious diseases. Clin Infect Dis 2004;38:1586-91

18 Sievert DM, Ricks P, Edwards JR, Schneider A, Patel J, Srinivasan A, et al. Antimicrobial-resistant pathogens associated with healthcare-associated infections: summary of data reported to the National Healthcare Safety Network at the Centers for Disease Control and Prevention, 2009-2010. Infect Control Hosp Epidemiol 2013:34:1-14.

19 Higgins JPT, Green S, eds. Cochrane handbook for systematic reviews of interventions version 5.1.0 [updated March 2011]. Cochrane Collaboration, 2011. www.cochranehandbook.org.

20 Downs SH, Black N. The feasibility of creating a checklist for the assessment of the methodological quality both of randomised and non-randomised studies of health care interventions. J Epidemiol Community Health 1998:52:377-84.

21 Woolf B. On estimating the relation between blood group and disease. Ann Hum Genet 1955;19:251-3.

22 DerSimonian R, Laird N. Meta-analysis in clinical trials. Control Clin Trials 1986;7:177-88.

23 Review Manager (RevMan) [Computer Program]. Version 5.1. Nordic Cochrane Center, Cochrane Collaboration, 2011

24 Konvalinka A, Errett L, Fong IW. Impact of treating Staphylococcus aureus nasal carriers on wound infections in cardiac surgery. $J$ Hosp Infect 2006;64:162-8.

25 Perl TM, Cullen JJ, Wenzel RP, Zimmerman MB, Pfaller MA, Sheppard D, et al. Intranasal mupirocin to prevent postoperative Staphylococcus aureus infections. N Engl J Med 2002;346:1871-7.

26 Segers P, Speekenbrink RG, Ubbink DT, van Ogtrop ML, de Mol BA. Prevention of nosocomial infection in cardiac surgery by decontamination of the nasopharynx and oropharynx with chlorhexidine gluconate: a randomized controlled trial. JAMA 2006:296:2460-6.

27 Bode LG, Kluytmans JA, Wertheim HF, Bogaers D, Vandenbroucke-Grauls CM, Roosendaal R, et al. Preventing surgical-site infections in nasal carriers of Staphylococcus aureus . N Engl J Med 2010;362:9-17.

28 Kalmeijer MD, Coertjens $\mathrm{H}$, van Nieuwland-Bollen PM, Bogaers-Hofman D, de Baere GA, Stuurman A, et al. Surgical site infections in orthopedic surgery: the effect of mupirocin nasal ointment in a double-blind, randomized, placebo-controlled study. Clin Infect Dis 2002;35:353-8.

29 Cimochowski GE, Harostock MD, Brown R, Bernardi M, Alonzo N, Coyle K. Intranasa mupirocin reduces sternal wound infection after open heart surgery in diabetics and nondiabetics. Ann Thorac Surg 2001;71:1572-8.

30 Coskun D, Aytac J. Decrease in Staphylococcus aureus surgical site infections following cardiovascular surgery. J Hosp Infect 2005;60:287-9.

31 Graf K, Sohr D, Haverich A, Kuhn C, Gastmeier P, Chaberny IF. Decrease of deep sternal surgical site infection rates after cardiac surgery by a comprehensive infection control program. Interact Cardiovasc Thorac Surg 2009;9:282-6.

32 Kluytmans JA, Mouton JW, VandenBergh MF, Manders MJ, Maat AP, Wagenvoort JH, et al. Reduction of surgical-site infections in cardiothoracic surgery by elimination of nasal carriage of Staphylococcus aureus . Infect Control Hosp Epidemiol 1996;17:780-5. 


\section{What is already known on this topic}

Surgical site infections (SSIs) are potentially preventable adverse events of cardiac and orthopedic operations SSIs significantly increase hospital length of stay, readmission rates, healthcare costs, and mortality rates

Clinicians and researchers have debated whether nasal decolonization or glycopeptide antibiotic prophylaxis reduce SSIs caused by Gram positive bacteria

\section{What this study adds}

Among patients undergoing cardiac or orthopedic surgery: Nasal decolonization with mupirocin ointment was protective against Gram positive SSIs Preoperative prophylaxis with anti-methicillin (meticillin) resistant Staphylococcus aureus (MRSA) antibiotics when given to all patients was not protective against Gram positive SSIs

A bundle that included nasal decolonization and anti-MRSA prophylaxis for MRSA carriers was significantly protective against Gram positive SSIs

33 Martorell C, Engelman R, Corl A, Brown RB. Surgical site infections in cardiac surgery: an 11-year perspective. Am J Infect Control 2004;32:63-8.

34 Nicholson MR, Huesman LA. Controlling the usage of intranasal mupirocin does impact the rate of Staphylococcus aureus deep sternal wound infections in cardiac surgery patients. Am J Infect Control 2006;34:44-8.

35 Coskun D, Aytac J. Decrease in Staphylococcus aureus surgical-site infection rates after orthopaedic surgery after intranasal mupirocin ointment. $J$ Hosp Infect 2004;58:90-1.

36 Gernaat-van der Sluis AJ, Hoogenboom-Verdegaal AM, Edixhoven PJ, Spies-van Rooijen $\mathrm{NH}$. Prophylactic mupirocin could reduce orthopedic wound infections. 1,044 patients treated with mupirocin compared with 1,260 historical controls. Acta Orthop Scand 1998;69:412-4.

37 Price CS, Williams A, Philips G, Dayton M, Smith W, Morgan S. Staphylococcus aureus nasal colonization in preoperative orthopaedic outpatients. Clin Orthop Relat Res 2008;466:2842-7.

38 Hacek DM, Paule SM, Thomson RB Jr, Robicsek A, Peterson LR. Implementation of a universal admission surveillance and decolonization program for methicillin-resistant Staphylococcus aureus (MRSA) reduces the number of MRSA and total number of $S$ aureus isolates reported by the clinical laboratory. J Clin Microbiol 2009;47:3749-52.

39 Wilcox MH, Hall J, Pike H, Templeton PA, Fawley WN, Parnell P, et al. Use of perioperative mupirocin to prevent methicillin-resistant Staphylococcus aureus (MRSA) orthopaedic surgical site infections. J Hosp Infect 2003;54:196-201.

40 Sankar B, Hopgood P, Bell KM. The role of MRSA screening in joint-replacement surgery. Int Orthop 2005:29:160-3.

41 Dhadwal K, Al-Ruzzeh S, Athanasiou T, Choudhury M, Tekkis P, Vuddamalay P, et al. Comparison of clinical and economic outcomes of two antibiotic prophylaxis regimens for sternal wound infection in high-risk patients following coronary artery bypass grafting surgery: a prospective randomised double-blind controlled trial. Heart 2007;93:1126-33.

42 Merrer J, Desbouchages L, Serazin V, Razafimamonjy J, Pauthier F, Leneveu M. Comparison of routine prophylaxis with vancomycin or cefazolin for femoral neck fracture surgery: microbiological and clinical outcomes. Infect Control Hosp Epidemiol 2006;27:1366-71.

43 Finkelstein R, Rabino G, Mashiah T, Bar-El Y, Adler Z, Kertzman V, et al. Vancomycin versus cefazolin prophylaxis for cardiac surgery in the setting of a high prevalence of methicillin-resistant staphylococcal infections. J Thorac Cardiovasc Surg 2002;123:326-32.

44 Niederhauser U, Vogt M, Vogt P, Genoni M, Kunzli A, Turina MI. Cardiac surgery in a high-risk group of patients: is prolonged postoperative antibiotic prophylaxis effective? $\mathrm{J}$ Thorac Cardiovasc Surg 1997;114:162-8.

45 Saginur R, Croteau D, Bergeron MG. Comparative efficacy of teicoplanin and cefazolin for cardiac operation prophylaxis in 3027 patients. The ESPRIT group. J Thorac Cardiovasc Surg 2000;120:1120-30.

46 Salminen US, Viljanen TU, Valtonen VV, Ikonen TE, Sahlman AE, Harjula AL. Ceftriaxone versus vancomycin prophylaxis in cardiovascular surgery. $J$ Antimicrob Chemother 1999;44:287-90.

47 Tyllianakis ME, Karageorgos AC, Marangos MN, Saridis AG, Lambiris EE. Antibiotic prophylaxis in primary hip and knee arthroplasty: comparison between cefuroxime and two specific antistaphylococcal agents. J Arthroplasty 2010;25:1078-82.

48 Vuorisalo S, Pokela R, Syrjala H. Comparison of vancomycin and cefuroxime for infection prophylaxis in coronary artery bypass surgery. Infect Control Hosp Epidemiol 1998:19:234-9.

49 Periti P, Stringa G, Mini E. Comparative multicenter trial of teicoplanin versus cefazolin for antimicrobial prophylaxis in prosthetic joint implant surgery. Italian Study Group for Antimicrobial Prophylaxis in Orthopedic Surgery. Eur J Clin Microbiol Infect Dis 1999;18:113-9.

50 Pear SM, Goldsmith DL, Williamson TH, Mandel D, Sethi GK, Arzouman DA, et al. Identification and voluntary reduction of vancomycin use for perioperative antibiotic prophylaxis during coronary artery bypass graft surgery. Infect Control Hosp Epidemiol 1998;19:513-5.

51 Spelman D, Harrington G, Russo P, Wesselingh S. Clinical, microbiological, and economic benefit of a change in antibiotic prophylaxis for cardiac surgery. Infect Control Hosp Epidemiol 2002;23:402-4.

52 Bull A, Worth M, Richards M. Vancomycin is inferior to anti-staphylacoccal beta-lactam antibiotics for prevention of surgical site infections due to methicillin-sensitive Staphylococcus aureus. [Abstract]. Interscience Conference on Antimicrobial Agents and Chemotherapy. Boston, MA, 2010:K-1180.

53 Gupta K, Strymish J, Abi-Haidar Y, Williams SA, Itani KM. Preoperative nasal methicillin-resistant Staphylococcus aureus status, surgical prophylaxis, and risk-adjusted postoperative outcomes in veterans. Infect Control Hosp Epidemiol 2011;32:791-6.
54 Sewick A, Makani A, Wu C, O'Donnell J, Baldwin KD, Lee GC. Does dual antibiotic prophylaxis better prevent surgical site infections in total joint arthroplasty? Clin Orthop Relat Res 2012;470:2702-7.

55 Soriano A, Popescu D, Garcia S, Bori G, Martinez JA, Balasso V, et al. Usefulness of teicoplanin for preventing methicillin-resistant Staphylococcus aureus infections in orthopedic surgery. Eur J Clin Microbiol Infect Dis 2006;25:35-8.

56 Jog S, Cunningham R, Cooper S, Wallis M, Marchbank A, Vasco-Knight P, et al. Impact of preoperative screening for meticillin-resistant Staphylococcus aureus by real-time polymerase chain reaction in patients undergoing cardiac surgery. $J$ Hosp Infect 2008;69:124-30

57 Walsh EE, Greene L, Kirshner R. Sustained reduction in methicillin-resistant Staphylococcus aureus wound infections after cardiothoracic surgery. Arch Intern Med 2011;171:68-73.

58 Kim DH, Spencer M, Davidson SM, Shaw JD, Gulczynski D, Hunter DJ, et al. Institutional prescreening for detection and eradication of methicillin-resistant Staphylococcus aureus in patients undergoing elective orthopaedic surgery. J Bone Joint Surg Am 2010;92:1820-6.

59 Sporer S, Hierstedt K, Coleman J, Abella L, Kelem R, Werkema J, et al. Preoperative Staphylococcus aureus screening to reduce surgical site infection [Abstract]. Paper No 471. American Academy of Orthopaedic Surgeons (AAOS) annual meeting, 2011:465.

60 Acebedo EC, Blatt S, Plummer L, Gonzales Y, Steinbrunner J. MRSA screening and decolonization before hip and knee replacement surgery to reduce infection and cost. [Abstract]. American College of Physicians Ohio Chapter, Columbus, OH, Oct 8-9, 2009.

61 Rao N, Cannella B, Crossett LS, Yates AJ Jr, McGough RL $3^{\text {rd }}$, Hamilton CW. Preoperative screening/decolonization for Staphylococcus aureus to prevent orthopedic surgical site infections. J Arthroplasty 2011;26:1501-7.

62 Hadley S, Immerman I, Hutzler L, Slover J, Bosco J. Staphylococcus aureus decolonization protocol decreases surgical site infections for total joint replacement. Arthritis 2010;2010:924518.

63 Schweizer ML, Furuno JP, Harris AD, Johnson JK, Shardell MD, McGregor JC, et al. Comparative effectiveness of nafcillin or cefazolin versus vancomycin in methicillin-susceptible Staphylococcus aureus bacteremia. BMC Infect Dis 2011;11:279.

64 Chang FY, Peacock JE Jr, Musher DM, Triplett P, MacDonald BB, Mylotte JM, et al. Staphylococcus aureus bacteremia: recurrence and the impact of antibiotic treatment in a prospective multicenter study. Medicine (Baltimore) 2003:82:333-9.

65 Crawford T, Rodvold KA, Solomkin JS. Vancomycin for surgical prophylaxis? Clin Infect Dis 2012:54:1474-9.

66 Bolon MK, Morlote M, Weber SG, Koplan B, Carmeli Y, Wright SB. Glycopeptides are no more effective than beta-lactam agents for prevention of surgical site infection after cardiac surgery: A meta-analysis. Clin Infect Dis 2004;38:1357-63.

67 Lador A, Nasir H, Mansur N, Sharoni E, Biderman P, Leibovici L, et al. Antibiotic prophylaxis in cardiac surgery: systematic review and meta-analysis. J Antimicrob Chemother 2012;67:541-50.

68 Van Rijen M, Bonten M, Wenzel R, Kluytmans J. Mupirocin ointment for preventing Staphylococcus aureus infections in nasal carriers. Cochrane Database Syst Rev 2008;(4):CD006216.

69 Courville XF, Tomek IM, Kirkland KB, Birhle M, Kantor SR, Finlayson SR. Cost-effectiveness of preoperative nasal mupirocin treatment in preventing surgical site infection in patients undergoing total hip and knee arthroplasty: a cost-effectiveness analysis. Infect Control Hosp Epidemiol 2012;33:152-9.

70 Lee AS, Macedo-Vinas M, Francois P, Renzi G, Schrenzel J, Vernaz N, et al. Impact of combined low-level mupirocin and genotypic chlorhexidine resistance on persistent methicillin-resistant Staphylococcus aureus carriage after decolonization therapy: a case-control study. Clin Infect Dis 2011:52:1422-30.

71 HCUP Nationwide Inpatient Sample (NIS). Healthcare Cost and Utilization Project (HCUP). 1997-2010. Agency for Healthcare Research and Quality, Rockville, MD. 2012. www. hcup-us.ahrq.gov/nisoverview.jsp.

Accepted: 16 April 2013

\section{Cite this as: BMJ 2013;346:f2743}

This is an Open Access article distributed in accordance with the Creative Commons Attribution Non Commercial (CC BY-NC 3.0) license, which permits others to distribute, remix, adapt, build upon this work non-commercially, and license their derivative works on different terms, provided the original work is properly cited and the use is non-commercial. See: http://creativecommons.org/licenses/by-nc/3.0/. 


\section{Tables}

Table 1| Risk of bias among observational studies as measured by Downs and Black subscales. Values in brackets are total scores achievable

\begin{tabular}{|c|c|c|c|c|c|}
\hline Studies by intervention & Reporting (11) & External Validity (3) & Internal validity-bias (7) & $\begin{array}{c}\text { Internal } \\
\text { validity-confounding } \\
(6)\end{array}$ & Sufficiently powered? \\
\hline \multicolumn{6}{|l|}{ Decolonization studies: } \\
\hline Cimochowski $2001^{29}$ & 9 & 3 & 3 & 1 & Yes \\
\hline Coskun $2005^{30}$ & 5 & 3 & 2 & 1 & No \\
\hline Graf $2009^{31}$ & 7 & 3 & 1 & 1 & Yes \\
\hline Kluytmans $1996^{32}$ & 8 & 3 & 3 & 1 & Yes \\
\hline Martorell $2004^{33}$ & 6 & 3 & 3 & 1 & Yes \\
\hline Nicholson $2006^{34}$ & 7 & 3 & 2 & 1 & Yes \\
\hline Coskun $2004^{35}$ & 7 & 3 & 2 & 1 & Yes \\
\hline Gernaat-van der Sluis $1998^{36}$ & 10 & 3 & 4 & 1 & No \\
\hline Price $2008^{37}$ & 8 & 3 & 3 & 2 & No \\
\hline Hacek $2009^{38}$ & 8 & 3 & 2 & 1 & Yes \\
\hline Sankar $2005^{40}$ & 6 & 3 & 1 & 1 & No \\
\hline Wilcox $2003^{39}$ & 7 & 3 & 3 & 1 & Yes \\
\hline \multicolumn{6}{|c|}{ Glycopeptide prophylaxis studies: } \\
\hline Pear $1998^{50}$ & 9 & 3 & 3 & 1 & No \\
\hline Spelman $2002^{51}$ & 9 & 3 & 4 & 1 & Yes \\
\hline Bull $2010^{52}$ & 6 & 3 & 2 & 2 & No \\
\hline Gupta $2011^{53}$ & 8 & 3 & 3 & 2 & No \\
\hline Merrer $2006^{42}$ & 8 & 3 & 3 & 2 & No \\
\hline Sewick $2012^{54}$ & 10 & 3 & 4 & 3 & No \\
\hline Soriano $2006^{55}$ & 9 & 3 & 2 & 1 & Yes \\
\hline \multicolumn{6}{|l|}{ Bundle studies: } \\
\hline Jog $2008^{56}$ & 6 & 3 & 3 & 1 & No \\
\hline Walsh $2011^{57}$ & 7 & 3 & 3 & 2 & Yes \\
\hline Kim $2010^{58}$ & 8 & 3 & 4 & 1 & Yes \\
\hline Sporer $2011^{59}$ & 5 & 3 & 1 & 1 & No \\
\hline Acebedo $2009^{60}$ & 7 & 3 & 1 & 1 & No \\
\hline Rao $2011^{61}$ & 7 & 3 & 3 & 2 & Yes \\
\hline Hadley $2010^{62}$ & 6 & 3 & 3 & 2 & No \\
\hline
\end{tabular}




\begin{tabular}{|c|c|c|c|c|c|c|}
\hline \multicolumn{7}{|c|}{ Table 2/ Stratified analyses } \\
\hline \multirow[b]{2}{*}{$\begin{array}{l}\text { Studies by } \\
\text { intervention }\end{array}$} & \multicolumn{6}{|c|}{ Pooled relative risk $(95 \% \mathrm{Cl})$} \\
\hline & All studies & Cardiac studies & $\begin{array}{l}\text { Total joint arthroplasty } \\
\text { or orthopedic studies }\end{array}$ & $\begin{array}{l}\text { Peer reviewed } \\
\text { publications* }\end{array}$ & $\begin{array}{c}\text { Randomized } \\
\text { controlled trials }\end{array}$ & $\begin{array}{l}\text { Observational } \\
\text { studies }\end{array}$ \\
\hline \multicolumn{7}{|l|}{ Decolonization studies: } \\
\hline Gram positive SSIs & $0.41(0.30$ to 0.55$) \dagger$ & $0.46(0.32$ to 0.67$) \dagger$ & $0.32(0.22$ to 0.47$)$ & $0.41(0.30$ to 0.55$) \dagger$ & $0.63(0.36$ to 1.13$) \dagger$ & $0.35(0.27$ to 0.46$)$ \\
\hline $\begin{array}{l}\text { Staphylococcus } \\
\text { aureus SSIs }\end{array}$ & 0.39 (0.31 to 0.50$)$ & $0.45(0.34$ to 0.58$)$ & $0.32(0.21$ to 0.47$)$ & 0.39 (0.31 to 0.50$)$ & 0.46 (0.29 to 0.73$)$ & 0.37 (0.28 to 0.49$)$ \\
\hline MRSA SSIs & $0.30(0.15$ to 0.62$) \dagger$ & $0.69(0.36$ to 1.31$)$ & $0.16(0.09$ to 0.28$)$ & $0.30(0.15$ to 0.62$) \dagger$ & NAt & 0.28 (0.12 to 0.62$)$ \\
\hline MSSA SSIs & 0.50 (0.37 to 0.69$)$ & $0.46(0.29$ to 0.72$) \dagger$ & $0.56(0.31$ to 1.01$)$ & 0.50 (0.37 to 0.69$)$ & $0.61(0.30$ to 1.25$) \dagger$ & $0.43(0.29$ to 0.62$) \dagger$ \\
\hline \multicolumn{7}{|l|}{$\begin{array}{l}\text { Glycopeptide } \\
\text { prophylaxis studies: }\end{array}$} \\
\hline Gram positive SSIs & $0.70(0.47$ to 1.04$) \dagger$ & $0.76(0.49$ to 1.18$) \dagger$ & $0.69(0.37$ to 1.30$)$ & $0.62(0.39$ to 0.98$) \dagger$ & $1.13(0.90$ to 1.42$)$ & $0.35(0.12$ to 1.03$) \dagger$ \\
\hline S aureus SSIs & $0.53(0.24$ to 1.16$) \dagger$ & $0.52(0.17$ to 1.56$) \dagger$ & $0.92(0.59$ to 1.44$)$ & $0.41(0.20$ to 0.84$)$ & $0.73(0.33$ to 1.63$)$ & $0.41(0.10$ to 1.64$) \dagger$ \\
\hline MRSA SSIs & $0.40(0.20$ to 0.80$)$ & $0.39(0.15$ to 1.03$)$ & $0.46(0.13$ to 1.63$) \dagger$ & $0.32(0.14$ to 0.73$)$ & $0.65(0.23$ to 1.82$)$ & $0.22(0.06$ to 0.81$) \dagger$ \\
\hline MSSA SSIS & 1.47 (0.91 to 2.38$)$ & 1.32 (0.82 to 2.12$)$ & 1.18 (0.65 to 2.13$)$ & 0.81 (0.38 to 1.73$)$ & $1.01(0.23$ to 4.54$)$ & $1.48(0.84$ to 2.60$)$ \\
\hline \multicolumn{7}{|l|}{ Bundle studies: } \\
\hline Gram positive SSIs & $0.41(0.30$ to 0.56$)$ & NA $\ddagger$ & $0.44(0.31$ to 0.65$)$ & $0.36(0.24$ to 0.53$)$ & NA§ & 0.41 (0.30 to 0.56$)$ \\
\hline$S$ aureus SSIs & 0.29 (0.19 to 0.42$)$ & NA & 0.33 (0.21 to 0.52$)$ & $0.27(0.15$ to 0.47$)$ & NA§ & 0.29 (0.19 to 0.42$)$ \\
\hline MRSA SSIs & $0.22(0.12$ to 0.38$)$ & NA $\ddagger$ & $0.27(0.14$ to 0.53$)$ & $0.19(0.10$ to 0.38$)$ & NA§ & $0.22(0.12$ to 0.38$)$ \\
\hline MSSA SSIs & $0.45(0.26$ to 0.78$)$ & NA & $0.42(0.23$ to 0.77$)$ & $0.52(0.27$ to 1.01$)$ & NA§ & $0.45(0.26$ to 0.78$)$ \\
\hline
\end{tabular}

SSIs=surgical site infections; MRSA=methicillin (meticillin) resistant $S$ aureus; NA=not available; MSSA=methicillin susceptible $S$ aureus.

*Only three studies were not peer reviewed (two bundle studies and one glycopeptide prophylaxis study) thus results of non-peer reviewed studies could not be pooled.

†Studies are heterogeneous $(P<0.1)$ and results should be interpreted with caution.

$\ddagger$ Not enough studies to pool.

$\S$ No randomized controlled trials were performed for this intervention. 


\section{Figures}

Articles or abstracts on surgical procedures $(n=1432)$

Excluded $(n=1358)$ :

Did not evaluate SSI as an outcome $(n=694)$

Did not evaluate Gram positive SSIs $(n=110)$

Did not include an intervention $(n=132)$

Evaluated other procedure types $(n=91)$

Studied pediatric cohorts $(n=79)$

Were reviews or commentaries $(n=74)$

Evaluated other surgical interventions $(n=68)$

Studied risk factors $(n=42)$

Studied treatment for current SSI $(n=19)$

Did not include a comparison group $(n=18)$

Studied animals or were done in a laboratory $(n=17)$

Written in a language other than English $(n=10)$

Studied a previous cohort $(n=3)$

Did mathematical modeling $(n=1)$

Articles identified for full review $(n=74)$

Excluded $(n=35)$ :

Compared two $\beta$ lactam antimicrobial agents $(n=8)$

Assessed antimicrobial timing $(n=6)$

Did not evaluate Gram positive SSIs $(n=5)$

Evaluated other surgical interventions $(n=5)$

Provided insufficient data $(n=4)$

Did not include a comparison group $(n=3)$

Studied risk factors $(n=2)$

Did not include an intervention $(n=1)$

Did mathematical modeling $(n=1)$

Articles included in meta-analyses $(n=39)$ :

Studied nasal decolonization $(n=17)$

Studied glycopeptide prophylaxis $(n=15)$

Studied decolonization and glycopeptide prophylaxis in a

bundle $(n=7)$

Fig 1 Literature search for articles on nasal decolonization or glycopeptide prophylaxis for preventing surgical site infections (SSIs) caused by Gram positive bacteria 


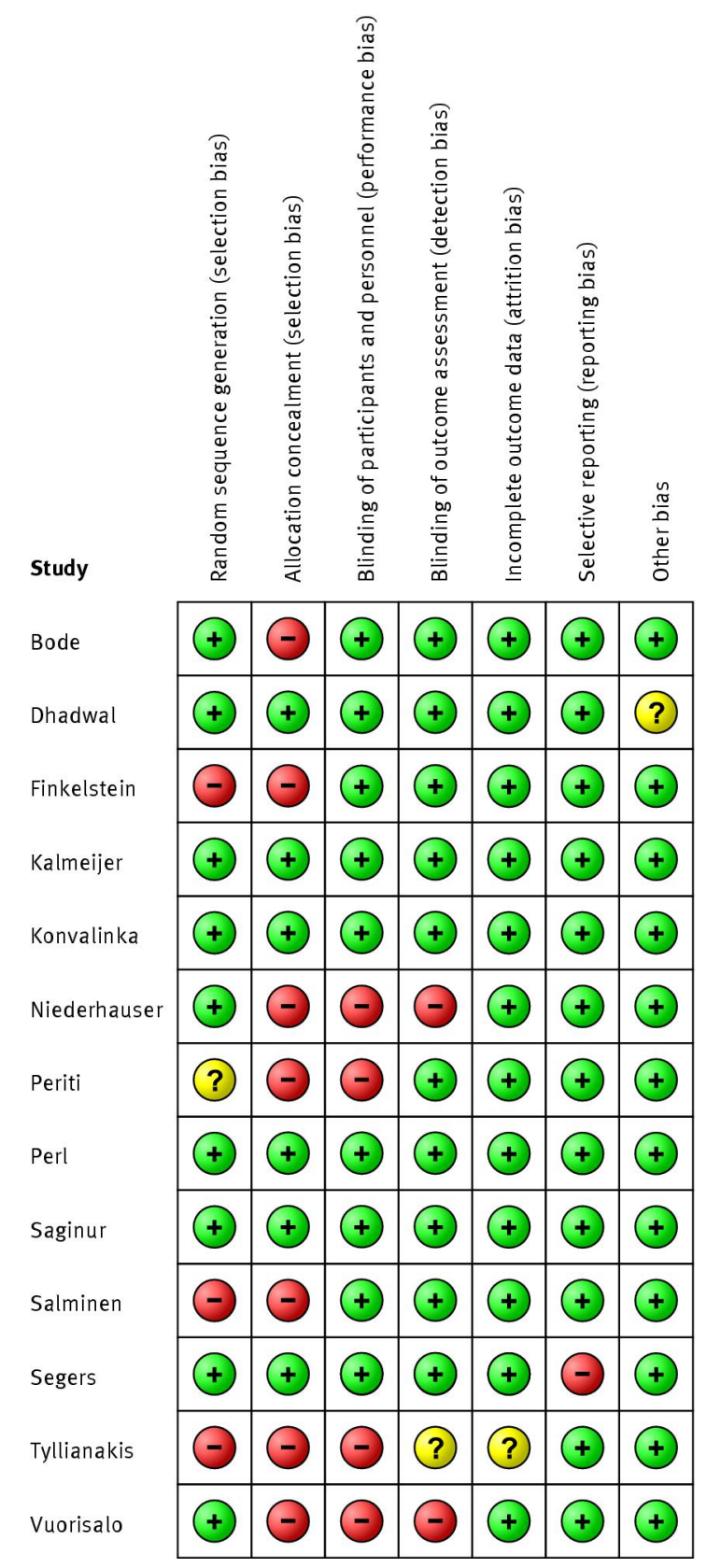

Fig 2 Risk of bias assessment for randomized controlled trials. + indicates low risk of bias, - indicates high risk of bias, and ? indicates unclear risk of bias 


\begin{tabular}{|c|c|c|c|c|c|c|c|}
\hline \multirow{3}{*}{$\begin{array}{l}\text { Study } \\
\text { Jog } 2008^{56}\end{array}$} & \multicolumn{2}{|c|}{ No of events/total } & & \multirow{2}{*}{\multicolumn{2}{|c|}{$\begin{array}{c}\text { Risk ratio }(95 \% \mathrm{Cl}) \\
\mathrm{M}-\mathrm{H}, \text { random }\end{array}$}} & \multirow[b]{2}{*}{$\begin{array}{l}\text { Weight } \\
\text { (\%) }\end{array}$} & \multirow[b]{2}{*}{$\begin{array}{c}\text { Risk ratio }(95 \% \mathrm{Cl}) \\
M-\mathrm{H}, \text { random }\end{array}$} \\
\hline & \multirow{2}{*}{$\begin{array}{c}\text { Intervention } \\
8 / 765\end{array}$} & \multirow{2}{*}{$\begin{array}{l}\text { Control } \\
13 / 697\end{array}$} & & & & & \\
\hline & & & & & & 12.4 & $0.56(0.23$ to 1.34$)$ \\
\hline Acebedo $2009^{60}$ & 9/1072 & $16 / 909$ & & & & 14.4 & $0.48(0.21$ to 1.07$)$ \\
\hline $\operatorname{Kim} 2010^{58}$ & $13 / 7019$ & $24 / 5293$ & & & & 20.9 & $0.41(0.21$ to 0.80$)$ \\
\hline Hadley $2010^{62}$ & $3 / 1644$ & $1 / 414$ & & & & 1.9 & $0.76(0.08$ to 7.24$)$ \\
\hline Rao $2011^{61}$ & $5 / 1440$ & $11 / 741$ & & & & 8.6 & $0.23(0.08$ to 0.67$)$ \\
\hline Sporer $2011^{59}$ & $18 / 3180$ & $17 / 1693$ & & & & 21.8 & $0.56(0.29$ to 1.09$)$ \\
\hline Walsh $2011^{57}$ & $10 / 2496$ & $42 / 2766$ & & $\rightarrow$ & & 20.1 & $0.26(0.13$ to 0.52$)$ \\
\hline Total $(95 \% \mathrm{Cl})$ & $66 / 17616$ & $124 / 12513$ & & $\phi$ & & 100.0 & $0.41(0.30$ to 0.56$)$ \\
\hline \multicolumn{8}{|c|}{ Test for heterogeneity: $\tau^{2}=0.00, \chi^{2}=4.50, \mathrm{df}=6$, } \\
\hline \multicolumn{3}{|c|}{$P=0.61, I^{2}=0 \%$} & 0.01 & 0.1 & 10 & 100 & \\
\hline \multicolumn{3}{|c|}{ Test for overall effect: $z=5.65, P<0.001$} & $\begin{array}{l}\text { Favo } \\
\text { inter }\end{array}$ & $\begin{array}{l}\text { urs } \\
\text { vention }\end{array}$ & & $\begin{array}{l}\text { lours } \\
\text { ntrol }\end{array}$ & \\
\hline
\end{tabular}

Fig 3 Forest plot of bundle intervention to prevent surgical site infections caused by Gram positive bacteria. All studies were observational

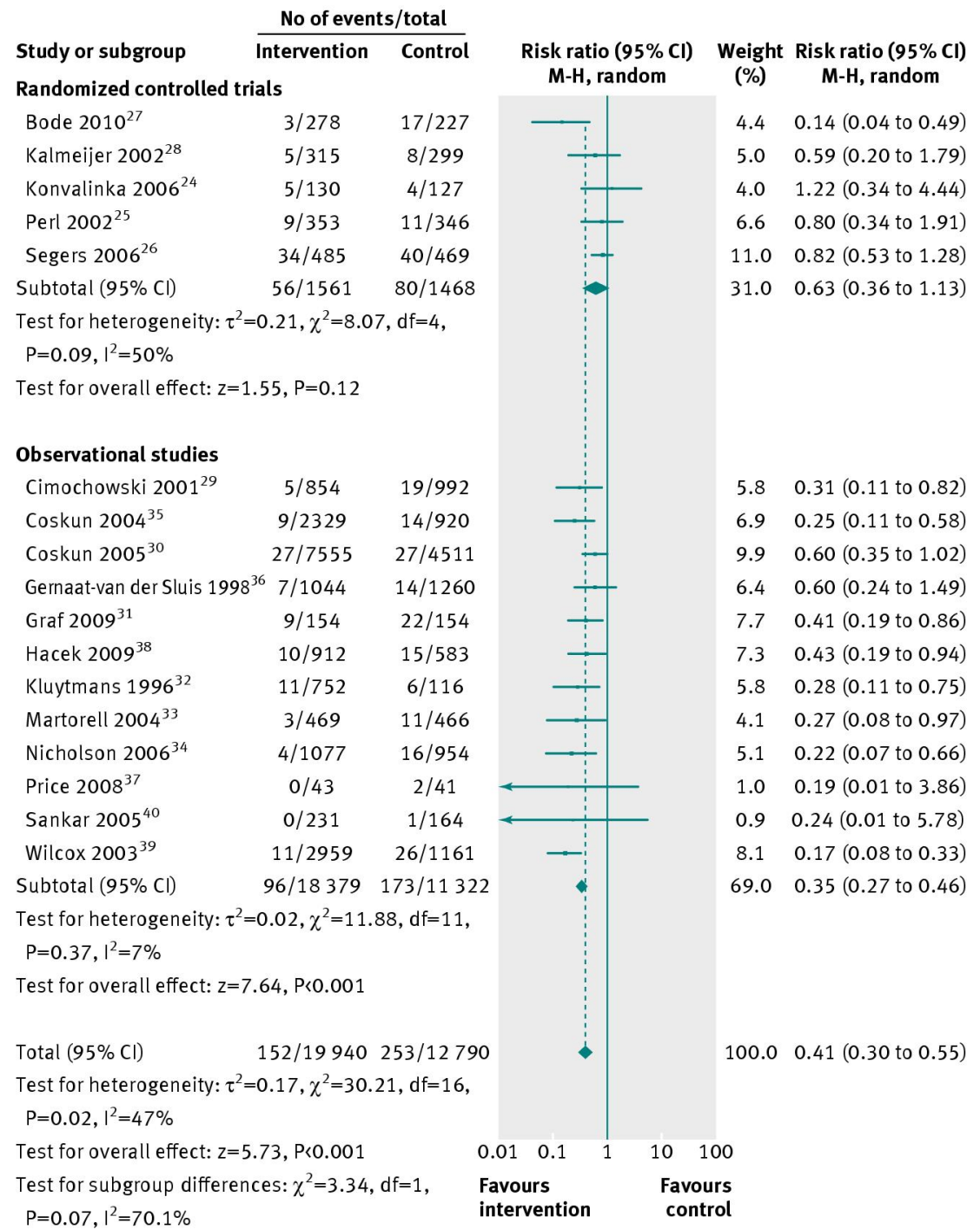

Fig 4 Forest plot of nasal decolonization to prevent surgical site infections caused by Gram positive bacteria, stratified by study design 


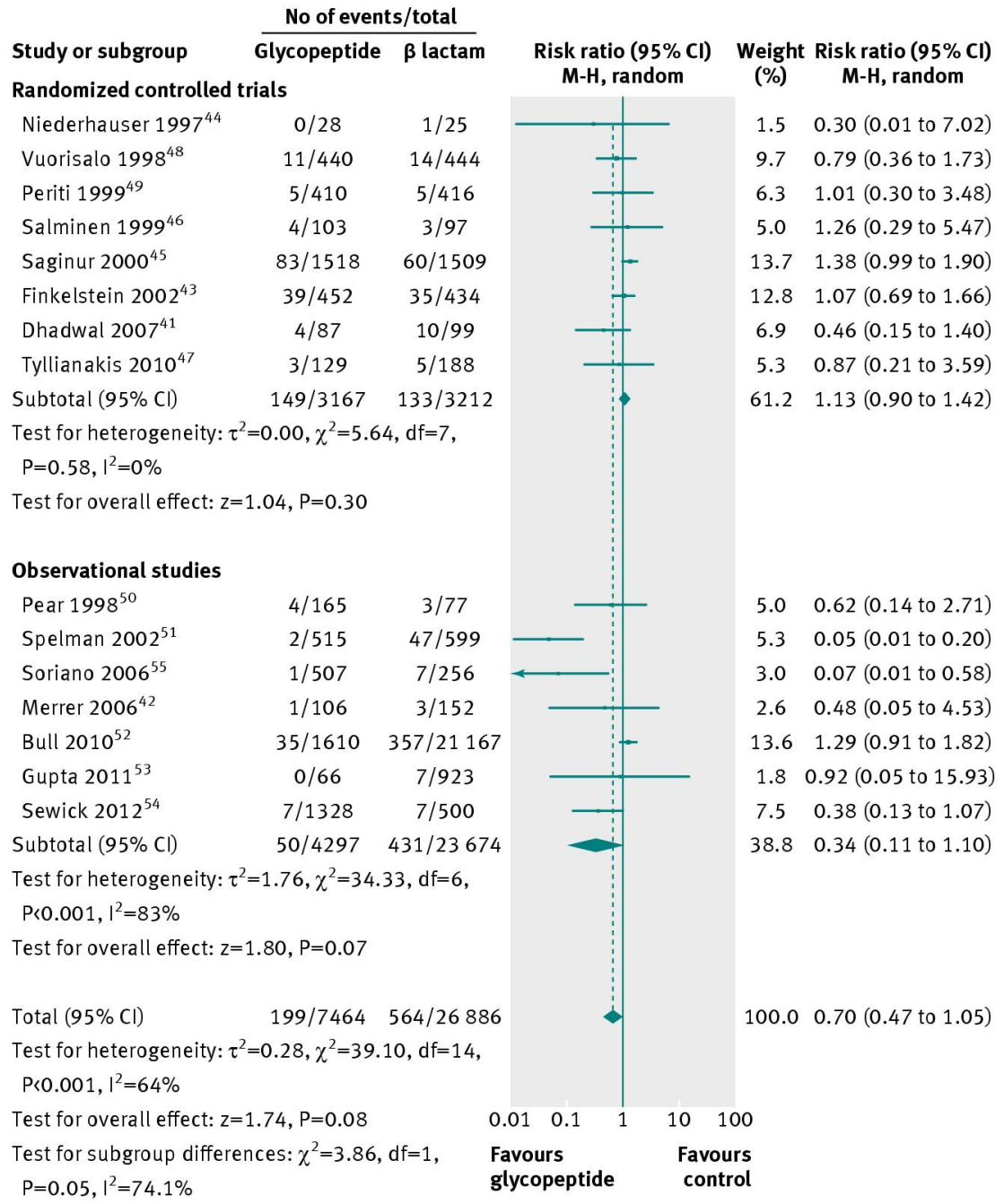

Fig 5 Forest plot of glycopeptide prophylaxis for all patients to prevent surgical site infections caused by Gram positive bacteria, stratified by study design 